\title{
INTERDIFFUSION AND GRAIN-BOUNDARY MIGRATION IN AU-Cu BILAYERS DURING ION-IRRADIATION
}

\author{
D. E. Alexander, L. E. Rehn, and P. M. Baldo \\ Materials Science Division \\ Argonne National Laboratory
}

Argonne, IL 60439

\section{November 1991}

The submitted manuscript has been
authored by a contractor of the U.S.
Government under contract No. W-31.
109-ENG-38. Accordingly. the U.S.
Government retains a nonexclusive,
royalty.tree license to publish or
reproduce the published form of this
contribution, or allow others to do so, for
U.S. Government purposes.

\section{DISCLAIMER}

. This report was prepared as an account of work sponsored by an agency of the United Stater Government. Neither the United States Government nor any agency thes ans liability or responsi-
employees, makes any warranty, express or implied, or assumes any legal lion, apparatus, product, or bility for the accuracy, completeness, or usefulness of any information, apparatys, owned rights. Referprocess disclosed, or represents, riiat its use would not infringe privately owned rights. Re trade name, trademark, ence herein to any specifi: crmmercial product, process, or service by trade namersement, recommendation, or favoring by the United States Government or any agency the and opinions of authors expressed herein do not

United States Government or any agency thereof.

Will be pr iented at the Fall Meeting of the Materials Research Society: Symposium A, Boston, MA, December 2-6, 1991.

\footnotetext{
*Work supported by the U.S. Department of Energy, BES-Material؟ Sciences, under contract \#W-31-109-ENG-38. 
Dale E. Alexander, L.E. Rehn and Peter M. Baldo

Materials Science Division, Argonne National Laboratory, Argonne, IL 60439

\section{ABSTRACT}

Ion irradiation and annealing experiments have been conducted on $\mathrm{Au} / \mathrm{Cu}$ bilayer films to evaluate the effect of irradiation on diffusion-induced grain boundary migration (DIGM). The Au films were prepared with a large-grained microstructure with grain boundaries perpendicular to the film surface and extending through the film thickness. Irradiations were conducted with $1.5 \mathrm{MeV}$ $\mathrm{Kr}$ at $228^{\circ} \mathrm{C}$. Rutherford backscattering spectrometry of the samples revealed that interdiffusion was substantially enhanced in the irradiated area relative to the unirradiated area. Both irradiated and annealed-only areas were characterized by a nearly uniform composition of 14 at.\% and 7 at.\% $\mathrm{Cu}$ respectively through the entire thickness of the underlying $\mathrm{Au}$ film. Small probe $\mathrm{X}$-ray energy dispersive spectroscopy showed significant lateral compositional homogeneities in both irradiated and annealed areas. These two results are consistent with previous observations of DIGM in the $\mathrm{Au} / \mathrm{Cu}$ system, suggesting that this previously unexamined interdiffusion mechanism contributes to ion beam mixing.

\section{INTRODUCTION}

Experimental ion beam mixing studies of bilayer metallic films have generally shown the existence of two temperature regimes [1]. In addition to a temperature-independent regime, a temperature-dependent regime typically begins near room temperature. The kinetic processes governing mixing in this thermally assisted regime are not well-understood. With few exceptions (for example ref.[2]), little effort has been made in evaluating the role of the initial microstructure of the films on subsequent mixing behavior in the temperature-dependent regime. One possible explanation, linking microstructural effects with enhanced mixing, is found in the phenomenon of diffusion-induced grain boundary migration (DIGM). DIGM, as summarized below, is an experimentally well-documented phenomena observed during low temperature $\left(<300^{\circ} \mathrm{C}\right)$ thermal interdiffusion in a large variety of bulk and thin-film bilayer couples [3]. Experiments assessing its role during ion beam mixing, however, are essentially absent from the literature.

Fig. 1 schematically illustrates the DIGM process in a thin bilayer sample. During thermal annealing, solute atoms from film B diffuse into the grain boundary of film A, inducing boundary migration to occur. An A-B solid solution alloyed zone develops in the wake of this migrated boundary. In DIGM, grain boundary migration and atomic interdiffusion occur at temperatures well below those required for conventional thermal grain growth and bulk diffusion. While observations of thermally-induced DIGM are common, the mechanism and drivirg force for this phenomenon remain the subject of considerable debate [3]. 
In this study, we sought to examine the effect of ion irradiation on DIGM in $\mathrm{Au} / \mathrm{Cu}$ bilayers. Previous experiments performed by Pan and Balluffi [4], and Grovenor [5], provide well-documented evidence of thermally-induced DIGM in $\mathrm{Au} / \mathrm{Cu}$ bilayer films, and therefore the system provides a good basis for irradiation studies. Ion beam mixing studies in $\mathrm{Au} / \mathrm{Cu}$ bilayers have also been previously performed $[6,7]$. The present work differs from previous studies in that the microstructure of the Au films, and the irradiation/annealing temperatures, were chosen to yield experimental conditions conducive to identifying DIGM.

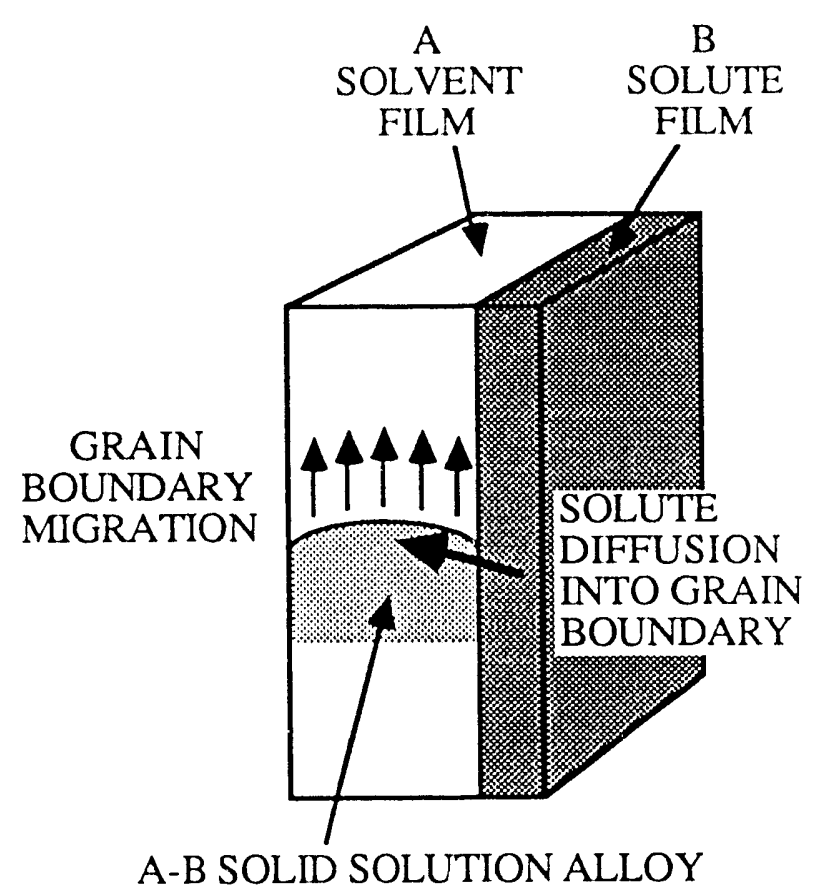

Fig. 1. Schematic of the DIGM process.

\section{EXPERIMENTAL}

Bilayer couples of $\mathrm{Au}$ and $\mathrm{Cu}$ were electron-beam evaporated onto (100) single crystal polished $\mathrm{MgO}$, and (100) cleaved $\mathrm{NaCl}$, in a vacuum system with the pressure not exceeding $1 \times 10^{-5}$ torr during Au deposition, or $3 \times 10^{-6}$ torr during $\mathrm{Cu}$ deposition. Samples were prepared by first evaporating 580-700 $\AA$ of Au onto the substrates, followed by $160 \AA$ of $\mathrm{Cu}$ onto the $\mathrm{Au}$. The Au films were made with a large-grained $(\sim 0.26 \mu \mathrm{m}$ diameter $)$ polycrystalline microstructure; the grain boundaries were predominantly oriented perpendicular to the film surface and spanned the film thickness. DIGM has been demonstrated previously in thermal experiments [4] with samples of this microstructural type. Two procedures were followed to obtain the Au films. In the first method, $\mathrm{Au}$ was evaporated onto $\mathrm{MgO}$ and $\mathrm{NaCl}$ at room temperature and subsequently annealed at $\sim 450^{\circ} \mathrm{C}$ for 1 hour. In the second method, Au was evaporated onto $\mathrm{MgO}$ held at $180^{\circ} \mathrm{C}$ during deposition. In both cases, the samples were cooled to room temperature prior to the deposition of the $\mathrm{Cu}$ overlayer.

1.5 MeV He Rutherford backscattering spectrometry (RBS) was used to analyze interdiffusion in the couples before, and after, irradiation and annealing treatments. Irradiations were performed at $228^{\circ} \mathrm{C}$ in the scattering chamber without breaking vacuum using $1.5 \mathrm{MeV} \mathrm{Kr}$ ions to doses $\leq 10^{15} \mathrm{~cm}^{-2}$. The range minus straggling of the ions at this energy was beyond the $\mathrm{Au} /$ substrate interface. After achieving the desired dose, the samples were cuoled at a rate $\sim 10^{\circ} \mathrm{C} / \mathrm{min}$ to room temperature. Both irradiated and unirradiated portions of the same sample were analyzed using RBS. RBS spectra were analyzed using RUMP [8].

Sample microstructure was examined by transmission electron microscopy (TEM) after floating th: films from their substraies onto Mo TEM grids. Distilled $\mathrm{H}_{2} \mathrm{O}$ was used to dissolve 
$\mathrm{NaCl}$ substrates; a warmed solution of $\mathrm{HCl}$ was used to remove films from the $\mathrm{MgO}$ and etch away any remaining $\mathrm{Cu}$ film. X-ray energy dispersive spectroscopy (XEDS) in a Phillips CM30 operated at $300 \mathrm{kV}$ was used to identify average and local $\mathrm{Cu}$ concentrations in the etched films using both large ( $>3 \mu \mathrm{m}$ diameter) and small ( $\leq 150 \AA)$ electron beam probes, respectively.

\section{RESULTS}

Fig. 2 shows RBS results of interdiffusion typically observed for a bilayer sample. In the as-evaporated state, the sample consisted of $160 \AA \mathrm{Cu}$ on $700 \AA$ of $\mathrm{Au}$. Interdiffusion of the $\mathrm{Cu}$ in $\mathrm{Au}$ is apparent after irradiating and annealing at $228^{\circ} \mathrm{C}$. Two important observations are made from Fig. 2 regarding $\mathrm{Cu}$ diffusion into the $\mathrm{Au}$ film. First, the enrichment of $\mathrm{Cu}$ in the $\mathrm{Au}$ can be attributed to two contributions: (1) local enrichment near the $\mathrm{Au} / \mathrm{Cu}$ interface, and (2) a nearly uniform enrichment of $\mathrm{Cu}$ extending through the entire thickness of the Au film. This uniform region is particularly evident over an $\sim 300 \AA$ thickness at the rear of the Au film. The second observation is that ion irradiation clearly enhanced both of these components. A factor of two increase in the uniform composition, from 7 to 14 at.\% $\mathrm{Cu}$, is observed after irradiation as determined by RUMP analysis of the spectra in Fig. 2.

TEM was performed on etched samples removed from $\mathrm{MgO}$ substrates after irradiation/annealing treatments and RBS analysis. A limited amount of small probe XEDS work demonstrated the presence of lateral compositional inhomogeneities. Attempts were made to probe the $\mathrm{Cu}$ concentration in grain boundary regions where DIGM may have occurred. However, in the irradiated regions, this was complicated by difficulty in identifying boundary regions due to the presence of irradiation damage. Probes were also placed at the center of grains which were easier to identify than boundary areas in TEM. The results for the sample whose RBS data is given in Fig. 2, along with large probe (film averaged) data, are summarized in Table I.

Selected area diffraction analysis of etched samples after irradiation and annealing showed only Au and solid solution $\mathrm{Cu}$ in $\mathrm{Au}$. No ordered phases were detected.

\section{DISCUSSION}

RBS analysis of interdiffusion and XEDS observation of lateral compositional inhomogeneities subsequent to irradiation or annealing are consistent with the occurrence of DIGM in the Au films. The nearly uniform $\mathrm{Cu}$ tail observed in Fig. 2 results because a fixed volume fraction of the Au film becomes alloyed with $\mathrm{Cu}$ through the film thickness. The XEDS measured enrichment of $\mathrm{Cu}$ in Au boundaries ( $\geq 20$ at.\% $\mathrm{Cu}$ ) is similar to the values (15-30 at.\% $\mathrm{Cu}$ ) measured previously by Pan and Balluffi in their thermal annealing experiments [4]. The annealing (RBS) results are comparable to those observed previously by Borders in an early study of thermal interdiffusion in $\mathrm{Au} / \mathrm{Cu}$ bilayer films [9]. An important observation in his 


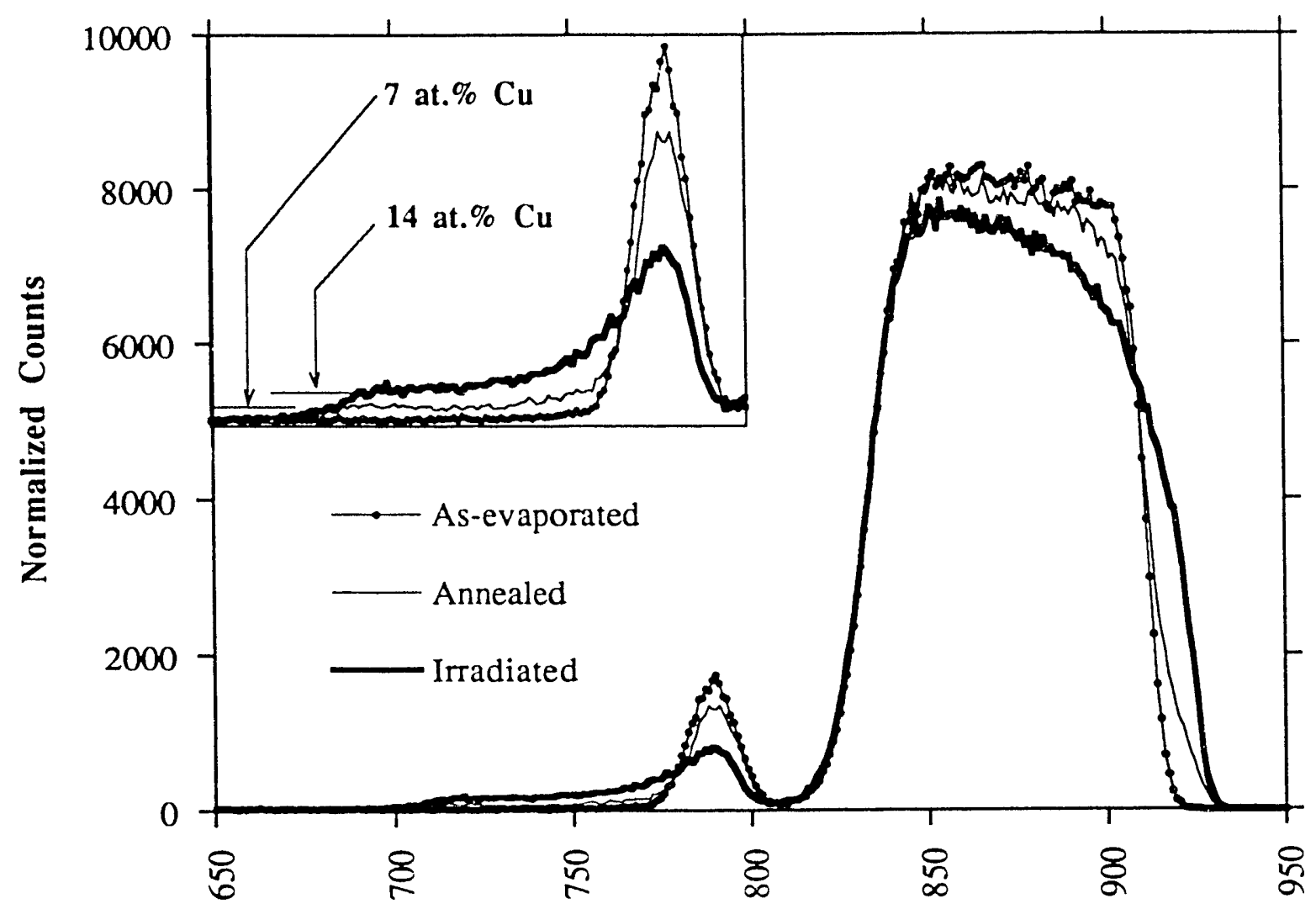

Channel

Fig. 2. RBS data showing $\mathrm{Au}$ and $\mathrm{Cu}$ signals obtained from a $\mathrm{Au} / \mathrm{Cu}$ bilayer on $\mathrm{MgO}$. Irradiation and annealing performed at $228^{\circ} \mathrm{C}$ for $\sim 40 \mathrm{~min}$. Inset shows an enlargement of the $\mathrm{Cu}$ signal.

Table I. XEDS average $\mathrm{Cu}$ concentration (at.\%) \pm standard deviation (at.\%) determined in irradiated and annealed-only regions of a $\mathrm{Au} / \mathrm{Cu}$ bilayer treated at $228^{\circ} \mathrm{C}$. Irradiation performed with $1.5 \mathrm{MeV} \mathrm{Kr}$ to a dose of $10^{15} \mathrm{~cm}^{-2}$. The number of samples taken for each average are indicated in parenthesis.

\begin{tabular}{|c|c|c|c|}
\hline \multirow{3}{*}{$\frac{\text { Treatment }}{\text { Annealed-only }}$} & \multirow{2}{*}{$\begin{array}{c}\overline{\mathrm{C}} \text {-Large Probe } \\
(\geq 3 \mu \mathrm{m} \text { diameter })\end{array}$} & \multicolumn{2}{|c|}{ Small Probe ( $\leq 150 \AA$ diameter) } \\
\hline & & $\mathrm{C}_{0}$-Grain Center & $\mathrm{C}_{\mathrm{B}}$-Grain Boundary \\
\hline & $9.2 \pm 2.9$ & $4.0 \pm 0.4$ & $20.3 \pm 0.2$ \\
\hline Irradiated & $16.7 \pm 0.8$ & $6.4 \pm 0.5$ & $24.6 \pm 1.7$ \\
\hline
\end{tabular}


study was that negligible interdiffusion, with no uniform $\mathrm{Cu}$ enrichment, occurred for $\mathrm{Cu}$ in single crystal $\mathrm{Au}$ at $228^{\circ} \mathrm{C}$. This demonstrated the importance of the Au microstructure (i.e. presence of grain boundaries) to interdiffusion.

Experiments by Akano et al. [2] on Ni-Pd bilayers suggested grain boundary diffusion as a possible mechanism for deeper penetration of solute in the solvent film. While grain boundary diffusion without DIGM may well be operative in our study, the magnitude of $\mathrm{Cu}$ enrichment observed in the Au film cannot be accounted for by this mechanism alone. Assuming a Au grain boundary width of $5 \AA$ and complete $C u$ saturation of these boundaries, the Au must have a grain size on the order of $200 \AA$ to achieve the smallest amount of uniform Cu enrichment ( 7 at. \% for annealing-only) determined by RBS. This grain size is about an order of magnitude less than what is actually measured in the films $(\sim 0.26 \mu \mathrm{m})$. Borders [9] came to the same conclusion in his work but, prior to the discovery of DIGM, remained uncertain as to the source of the enrichment.

The combined results of RBS and small probe XEDS suggest the development of a Au film microstructure as depicted in Fig. 3. Using this figure, the extent of DIGM may be evaluated. For the analysis, it is assumed that the microstructure of the polycrystalline Au film may be modelled as a hexagonal array of grains of average width, L, whose boundaries are perpendicular to the film surface and extend through its thickness. After either irradiation or annealing, $\mathrm{Cu}$ interdiffusion takes place, both uniformly along the $\mathrm{Au} / \mathrm{Cu}$ interface and via DIGM, as illustrated in Fig. 3. In the case of DIGM it is assumed that all grain boundaries migrate a distance, $\delta$, producing a solid solution alloyed zone that has a $\mathrm{Cu}$ atomic concentration, $\mathrm{C}_{\mathrm{B}}$. Clearly this is an idealization, since not all boundaries are expected to migrate. However, $\delta$, may be taken as the average over all migration distances. Interfacial mixing also contributes to enrichment of $\mathrm{Cu}$ in the $\mathrm{Au}$, and this is specified by the composition $\mathrm{C}_{0}$. Both of these contributions contribute to an average $\mathrm{Cu}$ atomic composition, $\overline{\mathrm{C}}$, as, for example, determined by a large XEDS probe. This analysis neglects any lateral interdiffusion induced by the ion beam between the DIGM alloyed zone and the adjacent grain. 


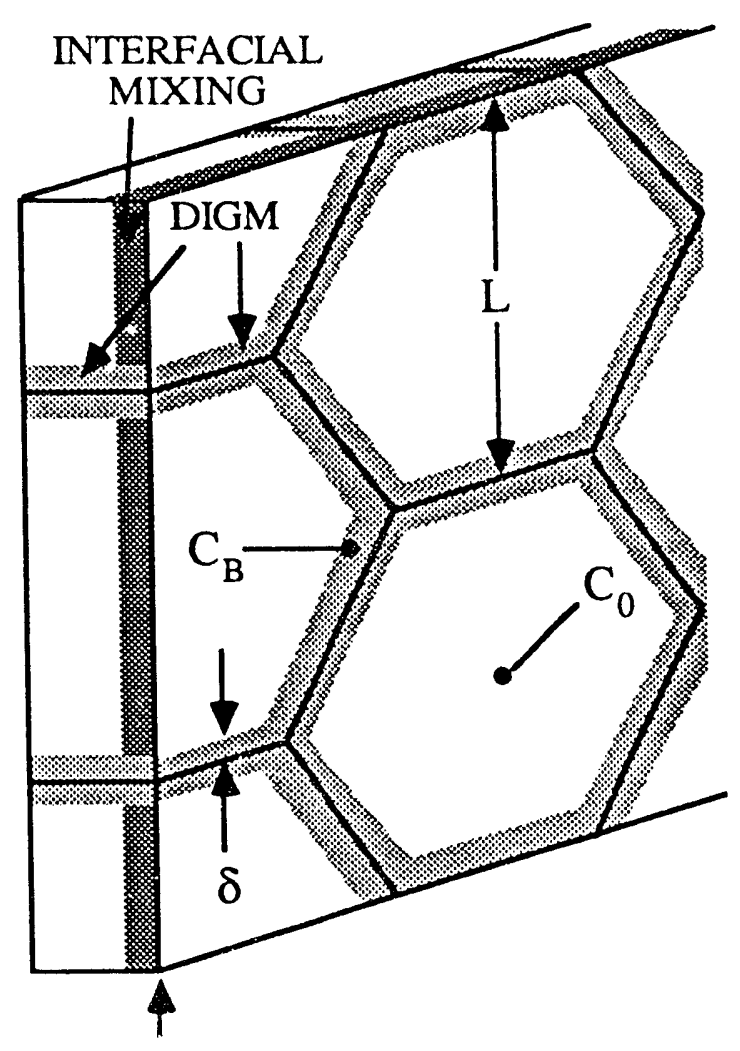

ORIGINAL INTERFACE

Fig. 3. Idealized picture of DIGM and interfacial mixing occurring in the $\mathrm{Au}$ film of a $\mathrm{Au} / \mathrm{Cu}$ bilayer subsequent to irradiation or annealing ( $\mathrm{Cu}$ film remuved).

Using simple geometric considerations, an expression may be derived relating the parameters shown in Fig. 3 and the filmaveraged $\mathrm{Cu}$ composition, $\overline{\mathrm{C}}$, which for $\delta \ll \mathrm{L}$ becomes,

$$
\frac{\mathrm{L}}{2 \delta}=\frac{\mathrm{C}_{\mathrm{B}}-\mathrm{C}_{0}}{\overline{\mathrm{C}}-\mathrm{C}_{0}}
$$

Combining the values in Table $\mathrm{I}$, and the measured grain size of $\mathrm{L} \approx 0.26 \mu \mathrm{m}$, the average distance of migrated boundary is estimated to be $\delta \approx 410 \AA$ for annealed-only regions, and $\delta \approx 730 \AA$ for irradiated regions.

As mentioned above, the mechanism of thermal DIGM is uncertain. One model suggests that a grain boundary Kirkendall effect occurs in the boundary of the solvent film [10]. Grain boundaries may be modelled as a series of stacked edge dislocations. If an unequal flux of solvent and solute atoms exists along these tilt boundaries, dislocation climb is induced, resulting in boundary migration and a "freezing-in" of the composition in the boundary wake. A process can clearly be envisioned in which the presence of freely-migrating defects produced by irradiation kinetically affects either the boundary diffusivity and/or dislocation climb, in turn enhancing the DIGM process.

It is unclear to what degree DIGM may operate during irradiation of initially fine-grained bilayer films of the type typically used in ion beam mixing experiments. However, as the results of this work indicate, DIGM can enhance interdiffusion during irradiation at relatively low temperatures. Hence, the existence of this phenomenon may well impact on the interpretation of ion beam mixing results in the thermally-assisted regime. Additional irradiation studies are clearly warranted to evaluate this phenomenon.

\section{ACKNOWLEDGEMENTS}

This work was funded by the U. S. Department of Energy, BES-DMS, under Contract \#W-31109-Eng-38. 


\section{REFERENCES}

[1] L.E. Rehn and P.R. Okamoto, Nucl. Instrum. Methods B 39, 104 (1989).

[2] U.G. Akano, D.A. Thompson, W.W. Smeltzer and J.A. Davies, J. of Mater. Res. 3, 1063 (1988).

[3] A.H. King, Inter. Mater. Rev. 32, 173 (1987).

[4] J.D. Pan and R.W. Balluffi, Acta Metall. 30, 861 (1982).

[5] C. R. M. Grovenor, Acta Metall. 33, 579 (1985).

[6] L.S. Hung, M. Nastasi and J.W. Mayer, J. Appl. Phys. 56, 1420 (1984).

[7] Z.L. Wang, J.F.M. Westendorp, S. Doorn and F.W. Saris in Metastable Materin's Formation by Ion Implantation edited by S.T. Picraux and W.J. Choyke (Mater. Res. S $\_.$ Proc. 7, 1982) p. 59.

[8] L.R. Doolittle, Nucl. Instrum. Methods B 9, 334 (1985).

[9] J.A. Borders, Thin Solid Films 19, 359 (1973).

[10] R.W. Balluffi and J.W. Cahn, Acta Metall. 29, 493 (1981). 


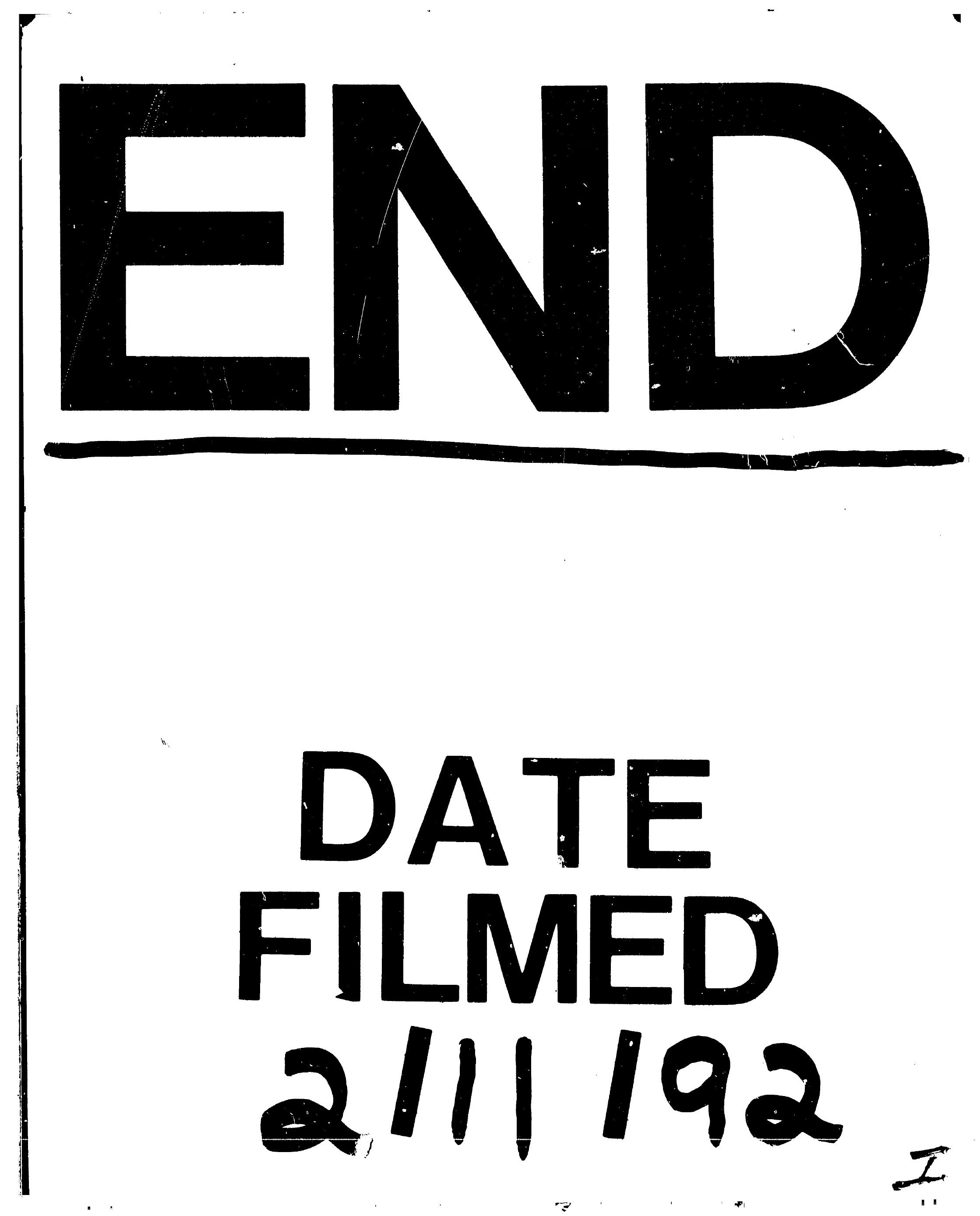



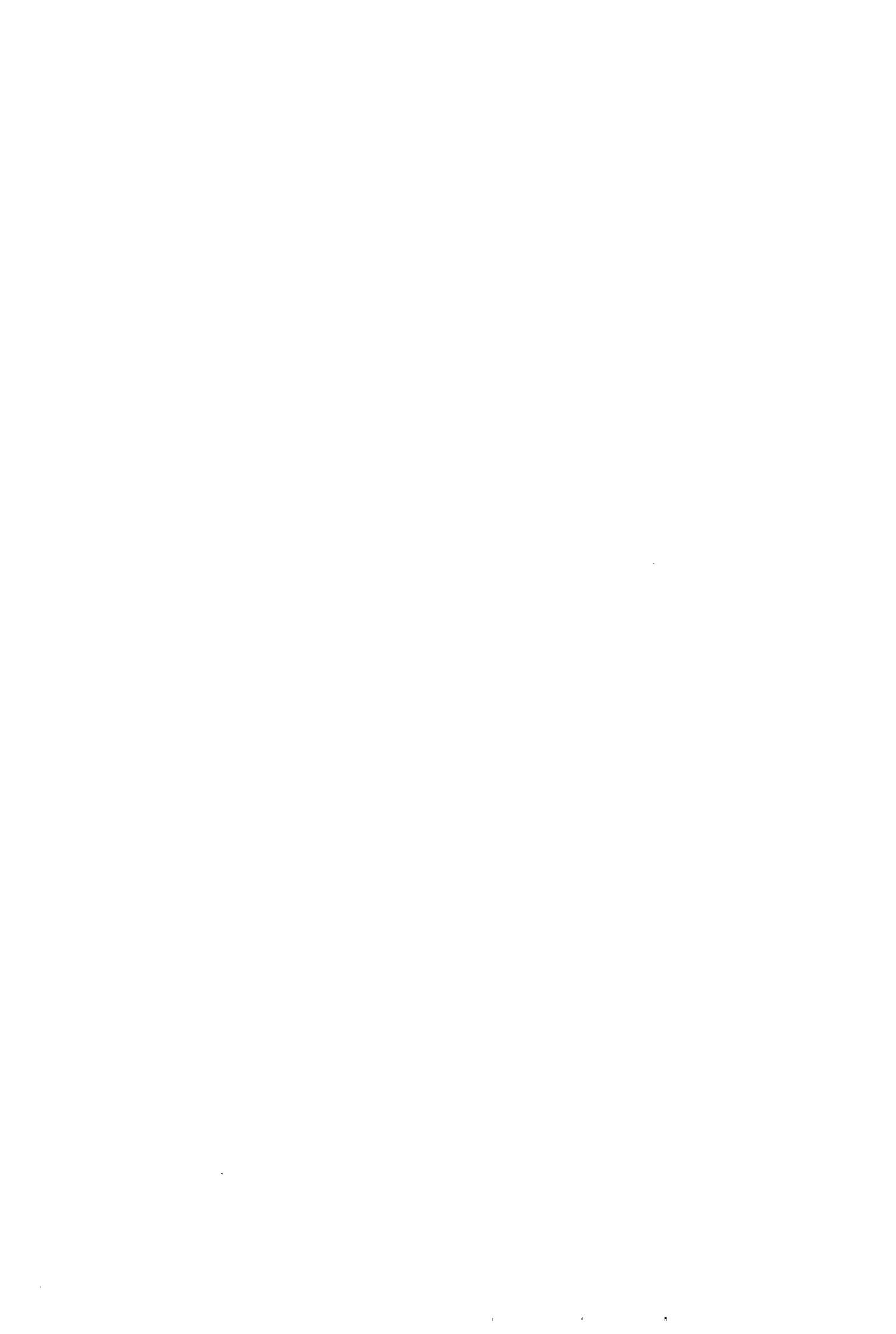